\title{
Rho Guanine Nucleotide Exchange Factor
} 1

National Cancer Institute

\section{Source}

National Cancer Institute. Rho Guanine Nucleotide Exchange Factor 1. NCI Thesaurus. Code C20942.

Rho guanine nucleotide exchange factor 1 (912 aa, 102 kDa) is encoded by the human ARHGEF1 gene. This protein plays a role in the regulation of transforming protein RhoAdependent signaling. 